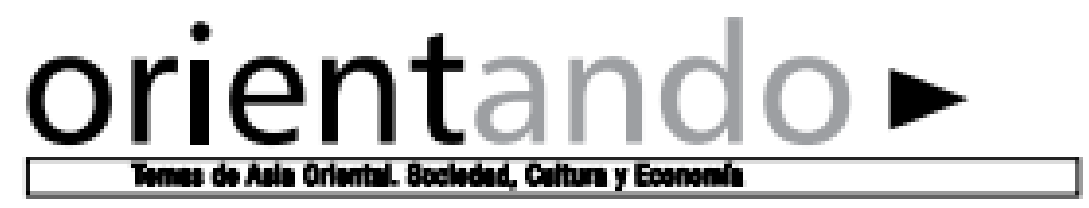

Año 11. Número 21. Octubre 2020-Marzo 2021

ISSN 2007-5723

Centro de Estudios China-Veracruz/Universidad Veracruzana

\title{
El comercio más sano en tiempo de pandemia: e-commerce. Panorama general en China-México
}

\section{Claudia Elilú Méndez Viveros ${ }^{1}$}

\section{Resumen:}

En el mundo de hoy, la digitalización de la economía es, más que una realidad, una necesidad. Los recientes hechos ocasionados por la pandemia originada por el virus SARS-CoV-2, han demostrado que las finanzas más estables son las que se acompañan de las nuevas tecnologías. En este sentido, el comercio electrónico o e-commerce, ha adquirido mayor terreno y popularidad no solo dentro de los países desarrollados, sino también en aquellos que se clasifican como naciones en vías de desarrollo; y es que la facilidad con la que se llevan a cabo las transacciones, sin necesidad de salir de casa, hace de esta modalidad de compra-venta, una de las opciones más seguras y efectivas dentro del mundo financiero.

De esta manera, el comercio online no solo ha impactado el mundo económico, también en la realidad humana y por supuesto la globalización. En el presente trabajo, se observará la realidad del e-commerce en China, su evolución durante y a raíz de la pandemia, además, de comparar estos hechos con los presentados dentro del territorio mexicano. Al mismo tiempo, se tratará de comprender su crecimiento acelerado e importancia a nivel mundial, por medio del análisis de las estadísticas presentadas y se reconocerán las oportunidades que representa el mercado chino, para México y el resto del mundo.

Palabras clave: comercio electrónico, economía digital, digitalización, Covid-19, pandemia.

\footnotetext{
1 Miembro del Centro de Estudios China-Veracruz (Cechiver) de la Universidad Veracruzana (UV), con cargo de Asistente de Investigación. Candidata al título de Maestra en Economía y Sociedad de China y América Latina por la

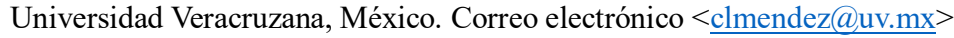




\begin{abstract}
:
In today's world, the digitization of the economy is more than a reality, a necessity. Recent events triggered by the SARS-CoV-2 pandemic have shown that the most stable finances are those accompanied by new technologies. In this sense, e-commerce has gained more ground and popularity not only within developed countries, but also in those that are classified as developing nations; and the fact is that the simple way with which transactions are carried out, without the need to leave home, makes this type of sale one of the safest and most effective options in the financial world.
\end{abstract}

In this way, online commerce has not only impacted the economic world, but also human reality and of course globalization. This work will observe the reality of e-commerce in China, its evolution during and as a consequence of the pandemic, besides to comparing these facts with those presented within the Mexican territory. At the same time, an attempt will be made to understand its accelerated growth and importance worldwide, through the analysis of the statistics presented and the opportunities that the Chinese market represents, for Mexico and the rest of the world, will be recognized.

Keywords: e-commerce, digital economy, digitization, Covid-19, pandemic.

\title{
1. Introducción
}

El presente artículo muestra los avances de la investigación titulada: El e-commerce, las Pymes veracruzanas y el mercado chino; texto elaborado como parte del proceso de titulación para obtener el grado de Maestra en Economía y Sociedad de China y América Latina, posgrado dictado por el Centro de Estudios China-Veracruz, de la Universidad Veracruzana.

La temática aquí expuesta, fue elegida por su pertinencia y relevancia en el mundo actual. El sistema comercial global principia una nueva etapa, en la cual los productos y servicios son comprados y vendidos, más recurrentemente, a través de medios electrónicos,

Orientando. Temas de Asia Oriental. Sociedad, Cultura y Economía. Revista editada por el Centro de Estudios China-Veracruz de la Universidad Veracruzana, México (Centro de Estudios APEC) / año 11 / número 21/ 
abriendo oportunidades y mercados que antes parecían muy lejanos y que ahora están al alcance de un click, beneficiando así a consumidores y vendedores.

Y es que, la transformación del comercio, gracias al uso y aplicación de la internet, ha impactado en todos los estratos comerciales, involucrando a Micro, Pequeñas y Medianas Empresas (Mipymes), que han descubierto en esta modalidad de negocios, una herramienta para acelerar su crecimiento, mejorar sus rendimientos $\mathrm{y}$, por supuesto, internacionalizarse.

De esta manera, incursionar en mercados electrónicos tan importantes y grandes como el mercado online chino, se ha convertido en un objetivo obligado para todas las empresas del mundo (grandes o pequeñas), ya que el número de consumidores y el poder adquisitivo de los mismos, crece y crece a ritmos estratosféricos que, además, han sido acelerados por la contingencia de la Covid-19.

Sin embargo, el e-commerce de occidente $y$ oriente, son experiencias completamente distintas, ya que el uso de redes sociales, medios de comunicación, marketplace, métodos de pago y por supuesto las particularidades de sus consumidores, difieren mucho. Por lo que, contar con un panorama que nos indique dónde estamos parados (cuánto hemos crecido en el comercio online, qué nos falta para mejorar este tipo de compra-venta, pronósticos de crecimiento, características diferenciadoras, desventajas, áreas de oportunidad, etc.) y que nos brinde los antecedentes de nuestro mercado objetivo, garantizará una prueba con mayores probabilidades de éxito, sobre todo cuando de Asia y particularmente de China se trata.

\section{Panorama mundial}

De acuerdo con medios de comunicación internacionales, el confinamiento de personas registrado entre los meses de marzo a mayo, alcanzó un número estimado en los más de tres mil millones de personas a nivel mundial (El Financiero, 2020), prácticamente la mitad de

Orientando. Temas de Asia Oriental. Sociedad, Cultura y Economía. Revista editada por el Centro de Estudios 
la población del planeta. Esto no solo impactó en el sector turístico, el medio ambiente o la economía del país, también lo hizo en el comercio y muy especialmente en la manera en la que compramos.

En una economía global cada vez más digitalizada, la cuarentena sirvió como catalizador para que aquellos países que tenían cierta resistencia a estas formas de consumo, se subieran al tren de la revolución tecnológica, adquiriendo productos de todo tipo, especialmente aquellos productos del comercio del retail o comercio minorista.

De esta forma, y con el empuje que ya traía consigo la compra y venta a través de internet, el e-commerce adquirió mayor relevancia, sobre todo porque mientras el comercio "común" o rutinario era prácticamente detenido, las ventas online mantenían andando la economía global, tanto así que aquellas marketplace de renombre: como Amazon, tuvieron que salir a contratar cerca de 100, 000 empleados, tan solo en Estados Unidos para poder cumplir con sus pedidos. (Ximénez, 2020)

Informes como digital 2020 (Gráfico 1), cuya fuente de información es Statista, una importante firma alemana de estadística mundial, muestra el cambio en el interés de los consumidores a través de la fluctuación en la demanda por artículos, entre los meses de enero a abril, esto a raíz del aislamiento provocado por la Covid-19.

Orientando. Temas de Asia Oriental. Sociedad, Cultura y Economía. Revista editada por el Centro de Estudios China-Veracruz de la Universidad Veracruzana, México (Centro de Estudios APEC) / año 11 / número 21/ 


\section{Gráfico 1. Covid 19: incremento en el interés a través de la compra online según el producto}

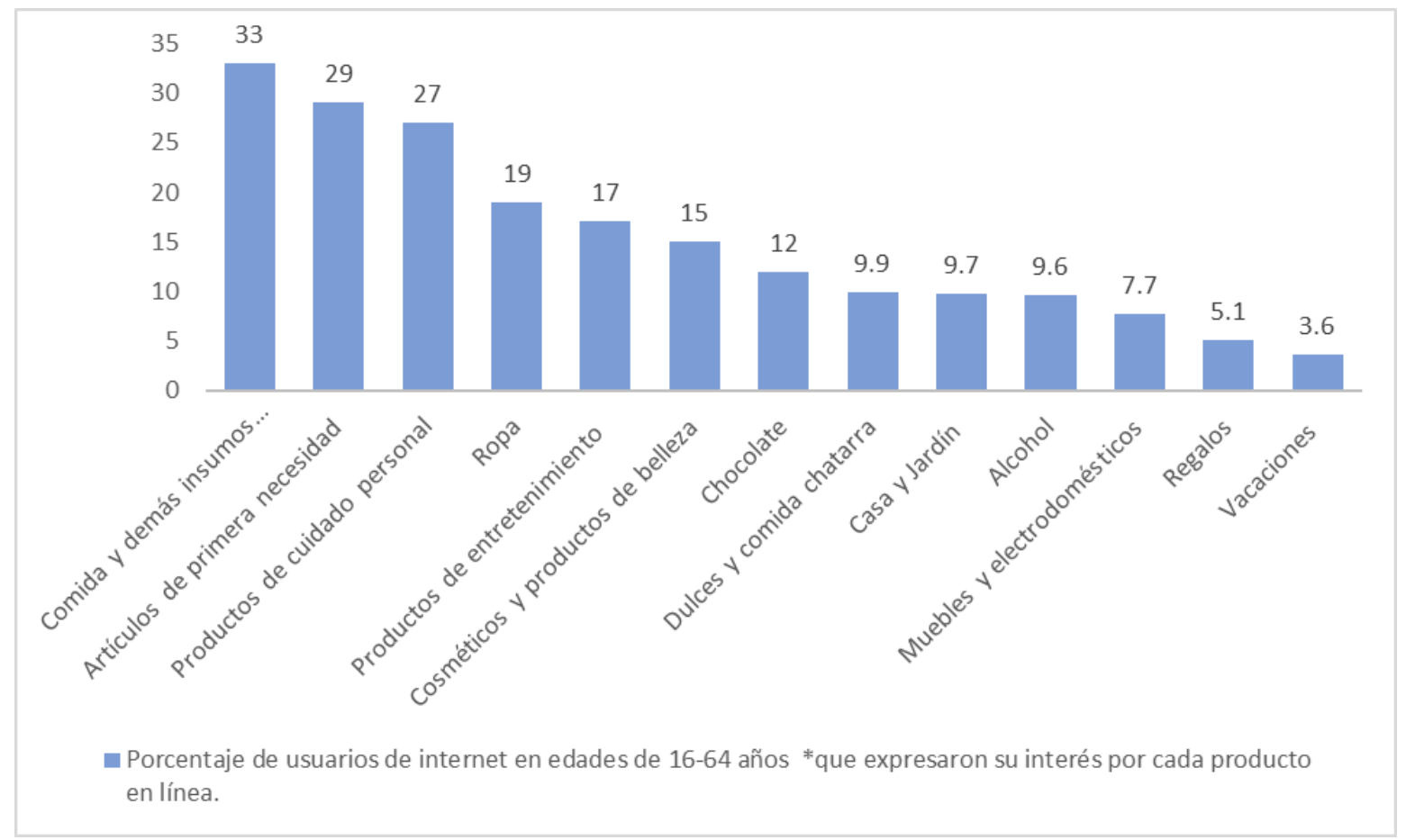

Fuente: Elaboración propia con datos de Globalwebindex's coronavirus multi-market study (wave 2, july 2020) Obtenido de: https://www.globalwebindex.com/hubfs/1.\%20Coronavirus\%20Research\%20PDFs/GWI\% 20coronavirus\%20findings\%20July\%202020\%20-\%20MultiMarket\%20Research\%20(Release\%2011).pdf.

Como se observa, los artículos alimenticios, aquellos clasificados como de primera necesidad y los productos de cuidado personal, adquirieron mayor importancia para los ciberconsumidores, generando una ventana de oportunidades para las empresas proveedoras de estos productos de la canasta básica, muy especialmente para las Mipymes locales.

Aunado a esto, el informe detalla las alteraciones el en tráfico de los sitios web de ecommerce, haciendo un comparativo con una fecha previa a la Covid-19 (Gráfico 2).

Orientando. Temas de Asia Oriental. Sociedad, Cultura y Economía. Revista editada por el Centro de Estudios China-Veracruz de la Universidad Veracruzana, México (Centro de Estudios APEC) / año 11 / número 21/ 


\section{Gráfico 2. Covid 19: impacto en el tráfico web del e-commerce (porcentaje de variación)}

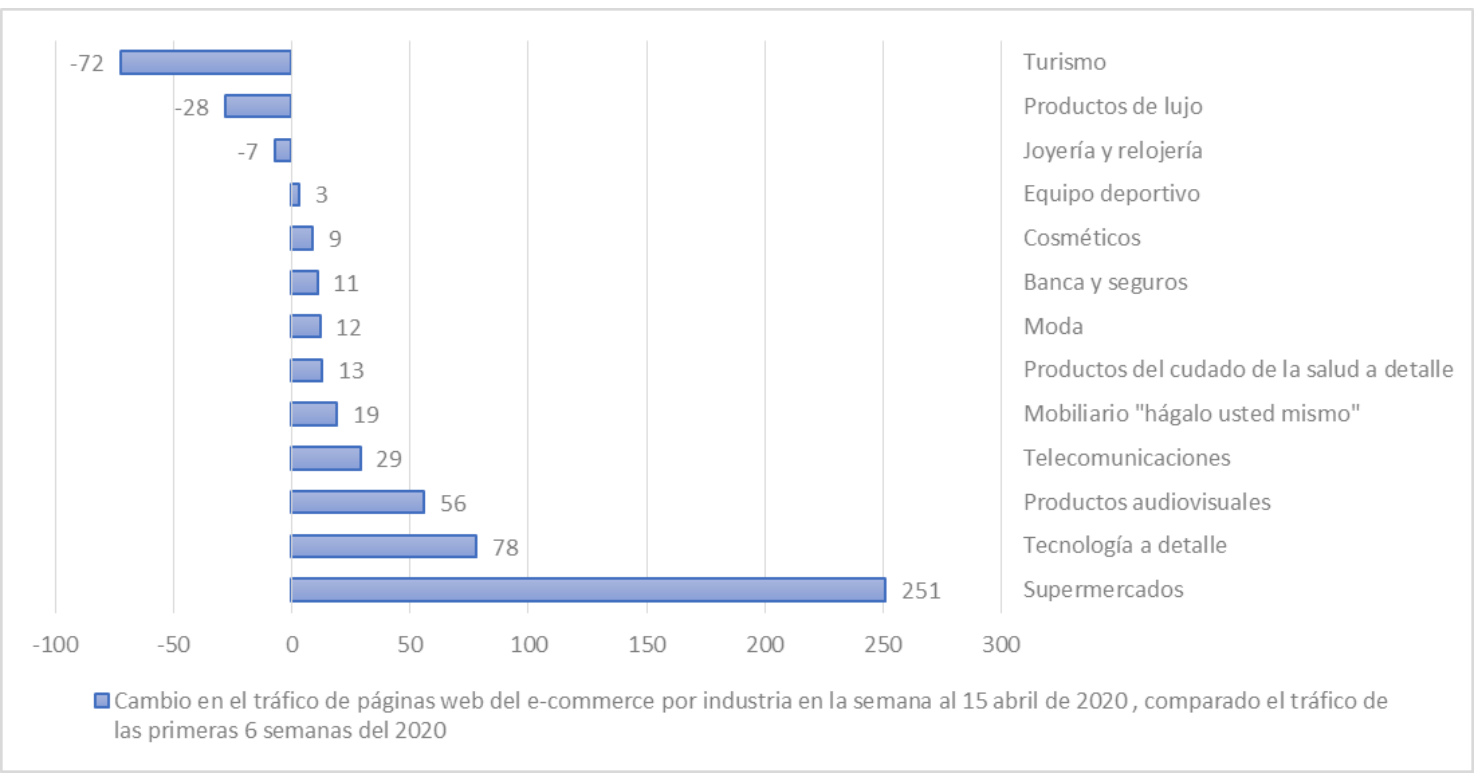

Fuente: Elaboración propia con datos de Globalwebindex’s coronavirus multi-market study (wave 2, july 2020) Obtenido de: https://www.globalwebindex.com/hubfs/1.\%20Coronavirus\%20Research\%20PDFs/GWI\% 20 coronavirus $\% 20$ findings $\% 20$ July $\% 202020 \% 20-\% 20$ MultiMarket\%20Research\%20(Release\%2011).pdf.

Confirmando que los sitios web que ofertan productos de la canasta básica, fueron los más beneficiados por causa de la pandemia. Así mismo, se denota el gran impacto negativo que el sector turismo está teniendo a diferencia de otros servicios como el entretenimiento.

Sumado a lo anterior, en el panorama mundial resalta el comportamiento del comercio electrónico en China, pues este país no solo se ha convertido en una potencia económica, política y militar, también destaca por su desarrollo tecnológico y por el crecimiento en su mercado online.

En este sentido, el país donde las personas dedicaron más tiempo a la compra por internet, en un rango de edades de 16 a 64 años: fue precisamente la República Popular China (RPCh) (Gráfico 3), rebasando por mucho el promedio global, seguido por Singapur, Orientando. Temas de Asia Oriental. Sociedad, Cultura y Economía. Revista editada por el Centro de Estudios

China-Veracruz de la Universidad Veracruzana, México (Centro de Estudios APEC) / año 11 / número 21/ 
Estados Unidos y la nación latinoamericana Brasil. Esto nos demuestra la importancia y la oportunidad que representa para las demás naciones del planeta, el mercado online chino, puesto que sus características en cuanto a número y capacidad de poder adquisitivo lo convierten en un objetivo obligado en el mundo de los negocios por internet.

\section{Gráfico 3. Covid 19: tiempo de compra en línea}

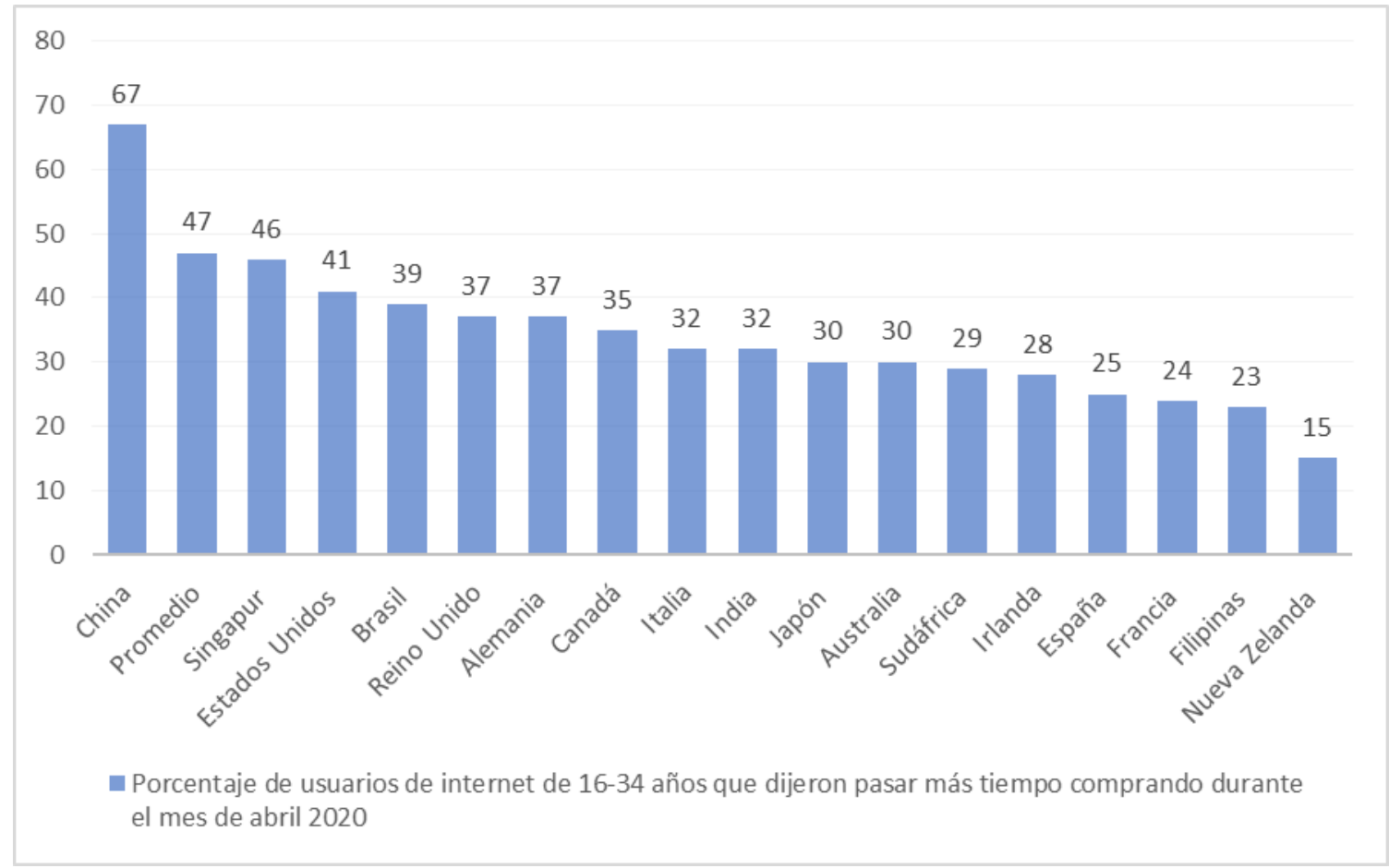

Fuente: Elaboración propia con datos de Globalwebindex's coronavirus multi-market study (wave 2, july 2020) Obtenido de: https://www.globalwebindex.com/hubfs/1.\%20Coronavirus\%20Research\%20PDFs/GWI\% 20coronavirus\%20findings\%20July\%202020\%20-\%20Multi-

Market\%20Research\%20(Release\%2011).pdf.

Orientando. Temas de Asia Oriental. Sociedad, Cultura y Economía. Revista editada por el Centro de Estudios China-Veracruz de la Universidad Veracruzana, México (Centro de Estudios APEC) / año 11 / número 21/ 


\section{China y el comercio electrónico}

Sin duda una perspectiva de lo que sucede a nivel mundial en materia de e-commerce, nos deja en claro la posición que juega China en esta actividad online, pero: ¿qué está sucediendo en la RPCh con esta modalidad de compra-venta?

China es el país más desarrollado en lo que se refiere a comercio electrónico, pero no se rige por los mismos modelos que caracterizan a esta actividad en el resto del mundo. Este crecimiento en tecnología inició a partir de las reformas de 1978 con la apertura a la IED, para 1997 había 620, 000 usuarios de Internet (MOFCOM, 2020), lo que equivalía al $0.05 \%$ de la población total.

Para junio de 2019, China tenía 854,49 millones de internautas (CNNIC, 2019), un aumento de 25.98 millones desde finales de 2018, y su penetración en Internet había alcanzado el $61.2 \%$, un aumento de 1.6 puntos porcentuales en comparación con el año 2018.

\section{Gráfico 4. Razones por las que los no internautas no acceden a internet}

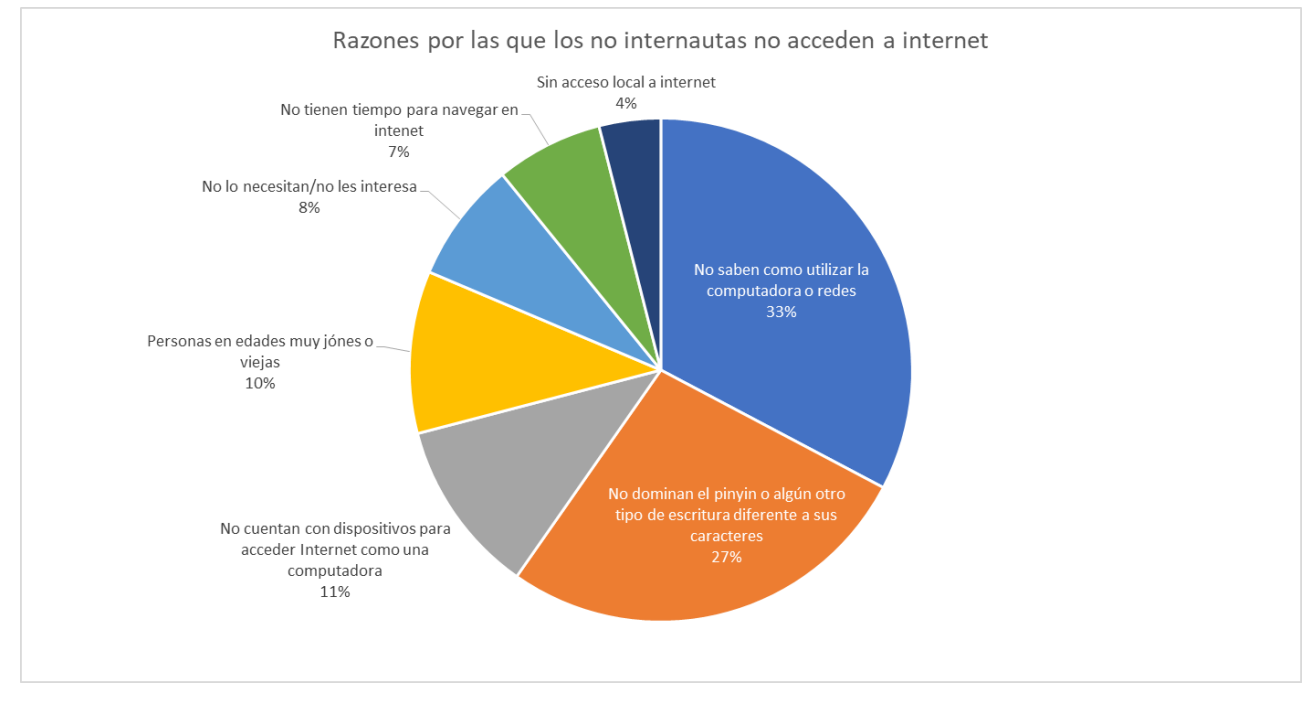

Fuente: Elaboración propiacon datos CNNIC Statiscal Survey on Internet Development in China 2019.

Orientando. Temas de Asia Oriental. Sociedad, Cultura y Economía. Revista editada por el Centro de Estudios China-Veracruz de la Universidad Veracruzana, México (Centro de Estudios APEC) / año 11 / número 21/ 
Mientras que el internet móvil para junio de 2019 contaba con 846.81 millones de usuarios, un aumento de 29.83 millones desde finales de 2018. Entre todos los usuarios de Internet, la proporción de quienes acceden a Internet a través de teléfonos móviles aumentó de $98.6 \%$ a fines de 2018 a 99.1\% (CNNIC, 2019).

Hasta junio de 2019, el tamaño del usuario de las compras en línea era de 638.82 millones o el $74.8 \%$ de la población total de internautas de China, 28.71 millones más que a finales de 2018. El número de usuarios de compras móviles alcanzó 621.81 millones, 29.89 millones más que a finales de 2018 , lo que representa el $73.4 \%$ de los usuarios de Internet móvil, tal y como se muestra en el Gráfico 5 Compras por internet e internet móvil.

\section{Gráfico 5. Compras por internet e internet móvil (millones de usuarios)}

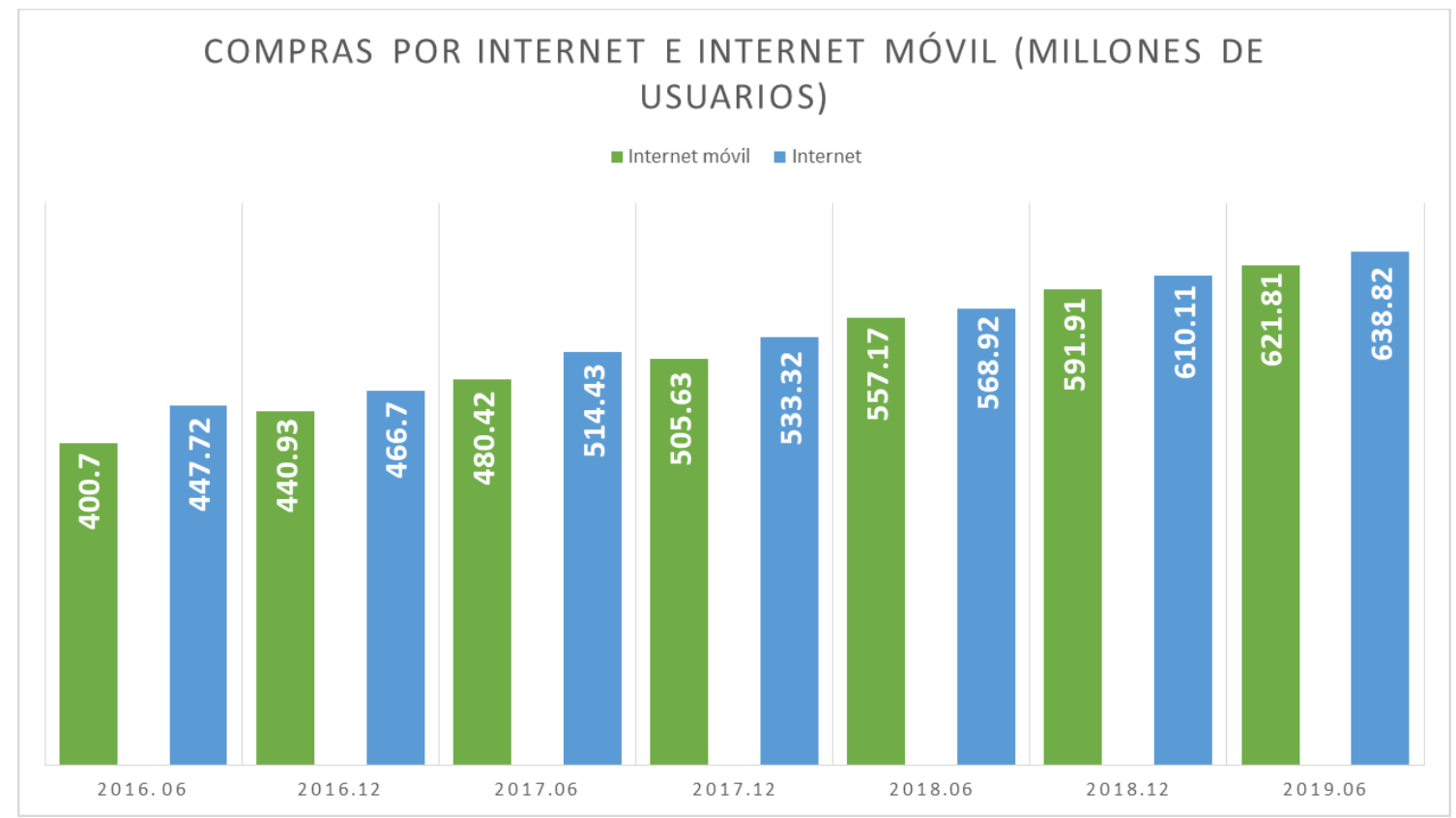

Fuente: Elaboración propia con datos CNNIC Statiscal Survey on Internet Development in China 2019.

Además, cabe mencionar que, en el primer semestre de 2019, el valor de las importaciones minoristas de comercio electrónico transfronterizo en China fue de 45.650 millones de yuanes, un aumento del 24.3\% anual. (PROCOMER, 2019).

Orientando. Temas de Asia Oriental. Sociedad, Cultura y Economía. Revista editada por el Centro de Estudios 
Estos vertiginosos hechos han propiciado la aparición de empresas gigantes como Alibaba, Tencent y JD.com que ya se encuentran entre las mayores compañías del mundo por capitalización bursátil. Lo que nos lleva a la pregunta: ¿Cuáles son las características propias del comercio electrónico dentro de la RPCh?

En primer lugar, ninguna red social, buscadores, marketplace o app es la que cotidianamente utilizamos en occidente como: Google, Facebook, Instagram, Twitter, Uber, etc. Esas aplicaciones móviles no funcionan en territorio chino. En este país el buscador número uno es Baidu, un motor de búsqueda que pertenece a una compañía de servicios web con sede en Beijing.

Baidu tiene un porcentaje de cuota de mercado del 81\% (Statista Digital Market Outlook, 2016), con el cual domina por completo las búsquedas entre los usuarios chinos desde el año 2016. Existen algunos otros que tienen un porcentaje de afluencia menor como son Sogou, Soso, Shenma y Haosu, por mencionar algunos, que aun cuando es relativamente un porcentaje bajo, no es nada desdeñable si recordamos el número de internautas que radican en China.

Por lo que respecta a los servicios de mensajería instantánea, el sustituto de WhatsApp es WeChat, una aplicación multipropósito desarrollada por Tencent (una compañía de la industria de telecomunicaciones considerada la más grande en temas de internet y la marca más cara de China). Esta aplicación ofrece además de los ya mencionados servicios de mensajería y llamada gratis, redes sociales, un sistema de pago online, servicios de transporte particulares como Didi (el Uber Chino) e incluso ha creado un espacio para citas parecido a Tinder, entre otros servicios. Convirtiéndola en una app completa y fácil de usar, superando por mucho lo que ofrecen las aplicaciones desarrolladas en occidente.

Por otro lado, los métodos de pago, también forman parte de las peculiaridades del comercio electrónico en este país, y en general de las particularidades de la evolución financiera de la nación asiática. El código QR, utilizado como procedimiento de pago, a

Orientando. Temas de Asia Oriental. Sociedad, Cultura y Economía. Revista editada por el Centro de Estudios 
través del escaneo por medio de un lector instalado en sus teléfonos inteligentes, es la forma generalizada con la que los ciudadanos asiáticos adquieren todos sus productos y servicios sin que ello genere comisiones.

Finalmente, en lo que respecta a los sitios de e-commerce más populares de la RPCh, el líder es Alibaba (que cuenta con un imperio), formado por un grupo de varias marcas en el mercado online, entre ellas la que lleva el nombre de la corporación: Alibaba, que comenzó en 1999. Marketplace abierto para compradores y vendedores de todo el mundo, es la marca estrella del imperio de Jack Ma. Posteriormente lanzó su versión light, por denominarla de cierto modo, conocida como Aliexpress; también está Taobao, una filial del grupo Alibaba fundada en 2003, que es el equivalente a nuestro más conocido eBay y Tmall, la cual se enfoca a la venta multiproducto, únicamente de aquellas empresas que están registradas en China (Galeano, 2019).

Por último, tenemos a JD.com que ha intentado diferenciarse de Alibaba y su plataforma Tmall mediante la gestión de un inventario propio para enviarlo directamente a los consumidores. De esta forma, en lugar de conectar compradores y vendedores (como hace Alibaba), consigue vender sus propios productos.

\section{El e-commerce mexicano}

México es un país considerado en vías de desarrollo, es decir posee una economía emergente que lo mantiene en un atraso tecnológico que se vuelve más evidente al compararse con países del primer mundo, como es el caso de China. A pesar de ello, el comercio electrónico ha ganado espacio en territorio mexicano, convirtiéndolo en uno de los mercados digitales más importantes y dinámicos de América Latina.

Según datos del Digital 2019 reports (Hootsuit \& we are social, 2019) México contabilizaba para este año una población total de 131.5 millones de personas, de los cuales

Orientando. Temas de Asia Oriental. Sociedad, Cultura y Economía. Revista editada por el Centro de Estudios China-Veracruz de la Universidad Veracruzana, México (Centro de Estudios APEC) / año 11 / número 21/ 
88 millones eran usuarios de internet; lo que representa más del 50\% de la población total; para ser más específicos ascendía al 66.9\%.

De este total de internautas el $92.70 \%$ de posee un teléfono móvil inteligente (smartphone), es decir, 81.58 millones aproximadamente de mexicanos tienen acceso al internet desde cualquier lugar y a cualquier hora a través de su dispositivo.

Estos números impactan de forma importante en las estadísticas del e-commerce nacional, puesto que el $65 \%$ del total de internautas adquieren productos vía online (Hootsuit \& we are social, 2019), sobre todo cuando consideran que los precios son bajos o cuenta con alguna promoción especial. En eventos o fechas puntuales como Black Friday, Hot Sale o el Buen Fin, las ventas por internet han reflejado sus números más altos.

Bajo este panorama, el $43 \%$ de los cibercompradores utilizan computadora para realizar las compras, mientras que el $46 \%$ lo hace a través de sus dispositivos móviles. Reflejando la marcada tendencia a comprar más a través de smartphones.

Derivado de ello, el valor del e-commerce en México ha tenido un aumento constante, esto según un estudio realizado por la Asociación de Internet MX (2019), importante firma en la República Mexicana. Como se muestra en el Gráfico 6 Estimación del valor del comercio electrónico en México, la tendencia al alza de este tipo de consumo se estimó en los 631.7 mil millones de pesos para el año 2019, un aumento de 28.6 puntos porcentuales con respecto al año inmediato anterior. Constante que se visualiza con los demás ejercicios anuales cuyos crecimientos oscilan entre el 20 y el 30 por ciento desde 2016.

Orientando. Temas de Asia Oriental. Sociedad, Cultura y Economía. Revista editada por el Centro de Estudios China-Veracruz de la Universidad Veracruzana, México (Centro de Estudios APEC) / año 11 / número 21/ 


\section{Gráfico 6. Estimación del valor del comercio electrónico en México}

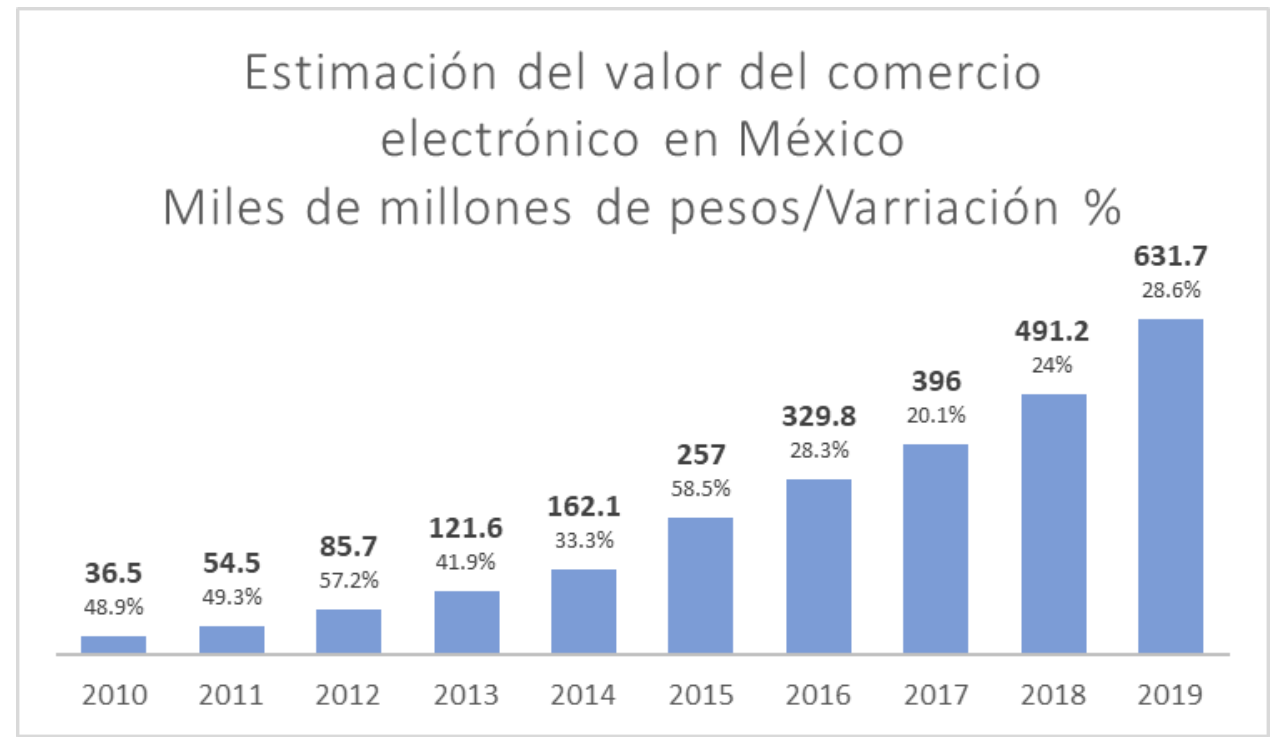

Fuente: Elaboración propia con datos de Asociación de Internet MX. 2019.

Estos datos, confirman la posición privilegiada que ocupa México en el mercado digital de Latinoamérica, además, evidencia de forma clara la áreas de oportunidad que el comercio electrónico para las ofrece a las empresas nacionales, especialmente aquellas catalogadas como Micro, Pequeñas y Medianas, las cuales han sido golpeadas fuertemente a causa del encierro provocado por la pandemia.

Por otro lado, y con el objetivo de comparar las características del e-commerce chino y mexicano, es importante mencionar los sitios preferidos por los habitantes del territorio americano para adquirir productos en línea: en primer lugar se encuentra Mercado Libre, cuyo origen es latino (Argentina); en segundo y tercer lugar están Amazon y Walmart, ambas compañías estadounidenses (Statista Global Consumer Survey, 2019) (Imagen 1).

A pesar del crecimiento de Alibaba y de su gran presencia en México, no figura entre los sitios preferidos por los mexicanos, sin embargo, no dudo que para los próximos dos años aparezca en la lista.

Orientando. Temas de Asia Oriental. Sociedad, Cultura y Economía. Revista editada por el Centro de Estudios 
orientando|维拉克鲁斯大学 中国-维拉克鲁斯研究中心

Orientando. Temas de Asia Oriental. Sociedad, Cultura y Economía. Revista editada por el Centro de Estudios China-Veracruz de la Universidad Veracruzana, México (Centro de Estudios APEC) / año 11 / número 21/ 


\section{Imagen 1. Las páginas de e-commerce preferidas en México}

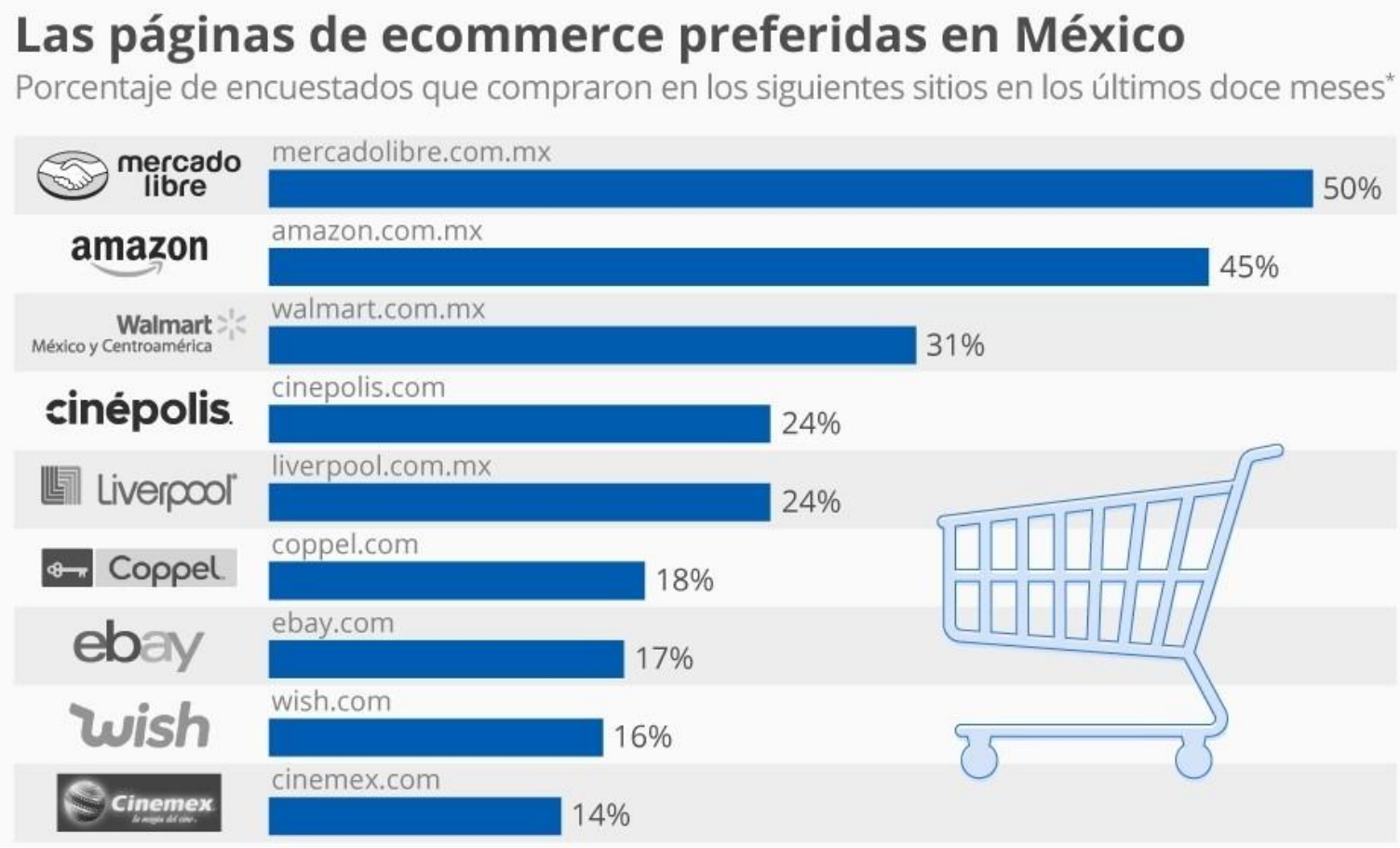

Fuente: Statista Global Consumer Survey. Obtenido de: https://es.statista.com/grafico/20123/las-paginas-de-ecommerce-preferidas-por-losmexicanos/. Encuesta realizada online a adultos (18 a 64 años) residentes en México entre e 04/04/2019 y el 15/05/2019. Varias respuestas posibles.

Por último, mencionaré las características de las pasarelas de pago más populares más utilizadas en México. Dentro del top 3, se encuentra: Mercado Pago, perteneciente al gigante en comercio electrónico sudamericano: Mercado Libre. Mercado Pago es una plataforma increíblemente completa y con una gran variedad de opciones, ya que cuentan con dispositivos para aceptar pagos con tarjeta (Blue Point) así como pagos con código QR ya que también es una wallet, lo que la convierte en la más completa en el territorio.

PayPal, marca estadounidense de alcance mundial; acepta solo pagos con tarjeta no en efectivo, lo que la deja en desventaja respecto a la anterior y además cobra comisión por cada transacción realizada. A pesar de ello, tienen la ventaja de poder realizar pago a meses sin intereses.

Orientando. Temas de Asia Oriental. Sociedad, Cultura y Economía. Revista editada por el Centro de Estudios China-Veracruz de la Universidad Veracruzana, México (Centro de Estudios APEC) / año 11 / número 21/ 
Por su parte, Conekta, marca recientemente posicionada en México, aliada con uno de los grandes vendedores del ratail: OXXO, acepta pagos en efectivo (principal cualidad), único diferenciador de las descritas anteriormente.

Cabe resaltar, que muy recientemente en Banco de México lanzó CODI (Cobro Digital), cuya similitud con el sistema de pagos chino es casi total, pues utiliza tecnología de códigos QR; pretende abrir la brecha para normalizar este tipo de cobros en el país. Sin embargo, aún se encuentra en su primera etapa, pues no es de uso generalizado entre la población, a pesar de que es obligatorio para todos los bancos y organizaciones financieras ofrecer este servicio.

\section{Conclusiones}

Sin duda, el comercio electrónico es ya toda una realidad, es el futuro del comercio como hasta ahora lo conocemos, cada día adquiere mayor terreno a nivel mundial y si México desea seguir siendo un mercado competitivo a nivel internacional, debe subirse a este tren de la digitalización.

Por su parte, el mercado online de China, posee una capacidad enorme, que además va en crecimiento. Esto también, como resultado de los esfuerzos que el gobierno ha realizado, porque cada vez más habitantes tengan acceso a internet. Recordemos (Gráfico 4 Razones por las que los no internautas no acceden a internet) que tan solo el $4 \%$ de los habitantes no internautas, los cuales forman parte de las zonas rurales, están clasificados en este rubro por no tener una conexión local.

Así pues, considero que las medidas y estrategias que China está implementando para impulsar aún más el e-commerce en su país, son una muestra de lo que podemos y deberíamos empezar a hacer en territorio mexicano. Empezando por gestionar zonas de "libre comercio electrónico", como las CBEC (Cross Border E-Commerce), zonas piloto localizadas en puntos específicos y claves del desarrollo digital chino, que simplifican los

Orientando. Temas de Asia Oriental. Sociedad, Cultura y Economía. Revista editada por el Centro de Estudios China-Veracruz de la Universidad Veracruzana, México (Centro de Estudios APEC) / año 11 / número 21/ 
trámites aduaneros y logísticos relacionados con el comercio electrónico.

Además, es indispensable que el gobierno de la República Mexicana, invierta fuertes sumas de dinero al desarrollo de IA (Inteligencia Artificial), redes cada vez más rápidas como la 5 y 6G, en parques tecnológicos, capacitación y educación para la futura mano de obra de una economía digitalizada, y en general al desarrollo de tecnología, que incluye todas las áreas del quehacer humano.

México comienza a dar pasos fuertes en este camino del comercio electrónico, y es por ello que debe aprovechar al máximo las oportunidades que China puede brindarle. Explotar su amplio mercado, que además cuenta con compradores con un poder adquisitivo de clase media alta, y sumarse a iniciativas y proyectos de alto impacto internacional como lo es la Nueva Franja y Ruta de la Seda, que contempla un espacio digital.

Es claro que, en algunos casos, el brote de la Covid-19, ha ocasionado cambios temporales como es el tan afectado sector de servicios. Sin embargo, en ciertas áreas, el coronavirus puede haber establecido un cambio duradero: como es el sector educativo y el comercio, por ello, los empresarios y sobre todo los Pequeños y Medianos Empresarios deberán incluir en sus estrategias de recuperación al comercio online.

\section{Referencias}

Asociación de Internet MX. (2019). Comercio electrónico en México. Asociación de Internet en MX. Obtenido de: https://www.asociaciondeinternet.mx/comercioelectronico-en-mexico

CNNIC. (2019). Statistical Report on Internet Development in China. Beijing, China: China Internet Network Information Center (CNNIC).

El Financiero. (2020). COVID-19 confina a la mitad de la población. El Financiero, economía, mercados y negocios. Obtenido de: https://www.elfinanciero.com.mx/mundo/covid-19-confina-a-la-mitad-de-lapoblacion.

Galeano, S. (2019). Quién es quién en el eCommerce chino: los nombres imprescindibles para vender en China. Marketing4ecommerce. Obtenido de: https://marketing4ecommerce.mx/quien-es-quien-en-el-ecommerce-chino-vender-

Orientando. Temas de Asia Oriental. Sociedad, Cultura y Economía. Revista editada por el Centro de Estudios 
en-china/

Global Web Index. (2020). Coronavirus Research, July 2020. Multi-market research wave 5. Londres, Reino Unido : GWI.

Hootsuit \& we are social. (2019). Digital 2019 reports. Londres, Reino Unido : Hootsuit \& we are social.

MOFCOM. (2020). MINISTRY OF COMMERCE PEOPLE'S REPUBLIC OF CHINA. Obtenido de http://english.mofcom.gov.cn/

PROCOMER. (2019). Crecen importaciones mediante comercio electrónico transfronterizo en China durante primer semestre. Promotora del Comercio Exterior de Costa Rica. Obtenido de: https://www.procomer.com/alertas_comerciales/crecen-importacionesmediante-comercio-electronico-transfronterizo-en-china-durante-primer-semestre/

Statista Global Consumer Survey. (2019). Las páginas de e-commerce preferidas en México. Berlín, Alemania: Statista.

Statista Digital Market Outlook (2016). Google domina en Occidente, Baidu en China. Obtenido de: https://es.statista.com/grafico/5561/google-domina-en-occidentebaidu-en-china/

Ximénez, P. (2020). Amazon busca contratar a 100.000 personas en Estados Unidos al dispararse los pedidos por el coronavirus. El País. Obtenido de: https://elpais.com/economia/2020-03-17/amazon-busca-contratar-a-100000personas-en-estados-unidos-al-dispararse-los-pedidos-por-el-coronavirus.html.

Orientando. Temas de Asia Oriental. Sociedad, Cultura y Economía. Revista editada por el Centro de Estudios China-Veracruz de la Universidad Veracruzana, México (Centro de Estudios APEC) / año 11 / número 21/ 